\title{
Familial thoracic aortic aneurysm/dissection with patent ductus arteriosus: genetic arguments for a particular pathophysiological entity
}

Philippe Khau Van Kien*,1,2 ${ }^{\star}$ Jean-Eric Wolf ${ }^{2,3}$, Flavie Mathieu ${ }^{1}$, Limin Zhu ${ }^{1}$, Nicolas Salve ${ }^{3}$, Alain Lalande ${ }^{2,4}$, Caroline Bonnet ${ }^{3}$, Gaëtan Lesca ${ }^{5}$, Henri Plauchu ${ }^{5}$, Arnaud Dellinger ${ }^{6}$, Annie Nivelon-Chevallier ${ }^{7}$, François Brunotte ${ }^{2,4}$ and Xavier Jeunemaitre ${ }^{1}$

\footnotetext{
${ }^{1}$ INSERM U36, Collège de France, and Département de Génétique, Hôpital Européen Georges Pompidou, Paris, France; ${ }^{2}$ Laboratoire de Pharmacologie et de Physiopathologie Cardiovasculaire Expérimentale, Université de Bourgogne, Dijon, France; ${ }^{3}$ Service de Cardiologie II, CHU, Dijon, France; ${ }^{4}$ Centre d'IRM, CHU, Dijon, France; ${ }^{5}$ Service de Génétique, Hôtel-Dieu, HCL, Lyon, France; ${ }^{6}$ Service de Cardiologie, Centre Hospitalier, Chalon-sur-Saône, France; ${ }^{7}$ Centre de Génétique, CHU, Dijon, France
}

Thoracic aortic aneurysm and aortic dissection (TAA and AD) are an important cause of sudden death. Familial cases could account for $20 \%$ of all cases. A genetic heterogeneity with two identified genes (FBN1 and COL3A1) and three loci (3p24-25 or MFS2/TAAD2, 5q13-q14 and 11q23.2-24) has been shown previously. Study of a single family composed of 179 members with an abnormally high occurrence of TAA/ $A D$ disease. A total of $\mathbf{4 0}$ subjects from three generations were investigated. In addition to five cases of stroke and three cases of sudden death, there were four cases of AD and four cases of TAA in adults. In all, 11 cases of patent ductus arteriosus (PDA) were observed, two of which were associated with TAA and one with AD. Segregation analysis showed that the distribution of these vascular abnormalities was more likely compatible with a single genetic defect with an autosomal dominant pattern of inheritance. There were no clinical signs of Marfan, Elhers-Danlos vascular type or Char syndromes. Genetic linkage analysis was performed for seven genes or loci implicated in familial TAA/AD disease (COL3A1, FBN1, 3p24-25 or MFS2) TAAD2, 5q13-q14 and 11q23.2-q24), Char syndrome (TFAP2B) or autosomal recessive PDA (12q24). Using different genetic models, linkage with these seven loci was excluded. Familial TAA/AD with PDA is likely to be a particular heritable vascular disorder, with an as yet undiscovered Mendelian genetic basis.

European Journal of Human Genetics (2004) 12, 173-180. doi:10.1038/sj.ejhg.5201119

Published online 14 January 2004

Keywords: genetics; linkage; aorta; aneurysm; dissection; ductus arteriosus

\section{Introduction}

Thoracic aortic aneurysm (TAA) and/or aortic dissection (AD) (MIM 132900) are an important cause of sudden

*Correspondence: Dr Philippe Khau Van Kien, Collège de France-INSERM U36-11, place Marcelin Berthelot, 75005 Paris, France.

Tel: + 331442716 55; Fax: + 331442716 91;

E-mail: pkhauvankien@chu-besançon.fr

Received 10 July 2003; revised 11 September 2003; accepted 10 October 2003 death. ${ }^{1-2}$ A retrospective study showed that they may account for $20 \%$ of all TAA and AD cases, and that several genes and several modes of inheritance are likely to be involved in this heterogeneous phenotypic entity. ${ }^{3}$ TAA/ $\mathrm{AD}$ is a common manifestation in Marfan syndrome (MFS) and less usual in Ehlers-Danlos syndrome (EDS) vascular type. ${ }^{4}$ To date, two genes have been identified: COL $3 A 1$ (type III procollagen $)^{5,6}$ and FBN1 (fibrillin-1) ${ }^{7,8}$ Two loci for nonsyndromic familial TAA/AD have been mapped to 5q13-q14 and 11q23.2-24 and called TAAD $1^{9}$ and FAA1, 
respectively. ${ }^{10}$ More recently, another locus for nonsyndromic familial TAA/AD was mapped to 3p24-25 and termed TAAD2. ${ }^{11}$ It overlaps a previously mapped second locus for MFS (MFS2). ${ }^{12}$

Another particular vascular syndrome that associates TAA/AD and patent ductus arteriosus (PDA) has been suggested in a single family. ${ }^{13}$ We report here the study of a large three-generation French family with further evidence for this peculiar inherited pathophysiological entity transmitted with an autosomal dominant mode of inheritance. Genetic linkage analysis excludes the responsibility of the previously described loci in syndromic and nonsyndromic familial TAA/AD, Char syndrome and recessive PDA.

\section{Subjects and methods Subjects}

This family was identified from a proband who underwent genetic counseling following the sudden death of his pregnant sister caused by an acute $\mathrm{AD}$ and because of the abnormal repetition of serious vascular events in his family. A total of 40 first-degree relatives from three generations were enrolled in the University Hospital of Dijon (France) for a clinical investigation protocol composed of two parts:

- a medical questionnaire involving available medical records, state of health and family history; a standardized clinical and ophthalmologic examination focused on classic signs of connective tissue disorders.

- a complete cardio-vascular examination, a transthoracic echocardiography and a thoracic MRI were carried out. Standard biochemical blood measurements with determination of fasting total and LDL-HDL cholesterol, triglycerides and glucose were also monitored. DNA from peripheral blood samples was obtained for all the 40 relatives and nine unrelated spouses.

A written consent form was obtained from all the subjects enrolled in this study - both approved of by the local ethic committee (Comité Consultatif de Protection des Personnes dans la Recherche Biomédicale de Bourgogne $n^{\circ}$ 2000/15; 00/03/16) and the French Ministry of Health.

\section{Methods \\ Transthoracic echocardiography, thoracic MRI and transesophageal echocardiography}

We used the well-defined method described by Roman et $\mathrm{al}^{14}$ for the transthoracic echocardiography measurements of the aortic root. Thoracic MRI was performed with a 1.5 T magnetic resonance whole-body imager. Gated spinecho T1-weighted and cineMRI sequences were obtained in multiple oblique planes parallel and perpendicular to the aortic longitudinal axis. The aortic diameters were measured in the best plane at each level of the thoracic aorta (aortic sinuses, sinotubular junction, ascending aorta, horizontal aorta, isthmus and descending aorta). We considered the limit values given by Higgins. ${ }^{15}$ Transesophageal echocardiography were carried out only when previous examinations were inconclusive. ${ }^{16}$ A positive status for TAA was retained when echocardiography and MRI measurements were concordant and exceeded the above-mentioned limit values. Discordant measurements were defined when the difference exceeded $2 \mathrm{~mm}$ between the two methods (unknown status).

\section{Segregation analysis}

Segregation analysis was performed using regressive models for binary traits based on logistic regression proposed by Bonney. ${ }^{17}$ Maximum likelihood was maximized under several models using the computer program REGRESS. ${ }^{18}$ When they nested, the restrictive model was tested versus the more general one by using the likelihood ratio test. ${ }^{19}$ In the non-nested case, we used the Akaike information criterion (AIC) defined by: $-2 \ln$ (Likelihood) $+2 p$, where $p$ is the number of estimated parameters.

\section{DNA analysis and polymerase chain reaction}

Genomic DNA was harvested from peripheral lymphocytes using standard procedures. Polymorphic markers were amplified using previously described conditions. ${ }^{20}$ The type and position of the markers are given in Table 2 .

\section{Linkage analysis}

Classical affected-only genetic linkage analysis of seven candidate loci was performed under a dominant model of inheritance. Two analyses were performed: in one case, only TAA and/or AD affected subjects were considered and in the other, PDA cases were included with the TAA/AD cases as affected subjects.

For the TAA/AD status, patients with AD (III:5, IV:7, IV:20, IV:22) and those with a TAA established with concordant echocardiography and MRI (IV:9, IV:11, IV:13, V:13) were considered to be affected. Others were considered to be of unknown status.

For the PDA status, patients with symptomatic or asymptomatic PDA discovered by screening (Table 1 and Figure 1) were considered to be affected. Patients without PDA demonstrated by echo-Doppler (IV:21, V:1, V:2, V:7, $\mathrm{V}: 8, \mathrm{~V}: 19)$ were considered to be unaffected. As there was no systematic screening for PDA in the family, the status of other individuals was considered to be unknown.

The phenocopy rate was fixed at 4/100000 for TAA/AD (average incidence in general population). ${ }^{1,2}$ Empirically, penetrance levels for carrier subjects were set at: $0 \%<20$ years old; $40 \%$ between 20 and 50 years old and $80 \%>50$ years old for TAA/AD, to take into account the likely age-dependent penetrance of the disease. ${ }^{21}$ When 
Table 1 Cardiovascular characterization of the 'Bourgogne' family

\begin{tabular}{|c|c|c|c|c|c|c|c|c|c|}
\hline Subject & Sex & $\begin{array}{l}\text { Year of } \\
\text { birth }\end{array}$ & $\begin{array}{l}\text { Height } \\
(\mathrm{cm})\end{array}$ & $\begin{array}{l}\text { Weight } \\
(\mathrm{kg})\end{array}$ & $\begin{array}{l}\text { Blood pressure } \\
\quad(\mathrm{mmHg})\end{array}$ & $\begin{array}{l}\text { Body surface } \\
\text { area }\left(m^{2}\right)\end{array}$ & Clinical data - medical history & $\begin{array}{c}\text { Indexed } \varnothing \text { with } \\
\text { BSA of aortic sinuses } \\
\left(\mathrm{cm} / \mathrm{m}^{2}\right) / \text { absolute } \\
\varnothing \text { of ascending } \\
\text { aorta (mm) with } \\
\text { TTE }\end{array}$ & $\begin{array}{l}\quad \varnothing \text { of aortic } \\
\text { sinuses/ascending } \\
\text { aorta/horizontal } \\
\text { aorta/isthmus } \\
\text { (mm) Spin echo T1 } \\
\text { weighted MRI }\end{array}$ \\
\hline II:1 & $\mathrm{F}$ & - & - & - & - & - & SD at 20 years old & - & - \\
\hline $\mathrm{II}: 2$ & $\mathrm{M}$ & - & $<175$ & - & - & - & - & - & - \\
\hline III:1 & $\mathrm{F}$ & 1917 & - & - & - & - & Died from stroke at 65 years old & - & - \\
\hline III:3 & $\mathrm{F}$ & 1920 & 149 & - & - & - & $\begin{array}{l}\text { PDA treated in the childhood. Died from a } \\
\text { breast cancer at } 57 \text { years old }\end{array}$ & - & - \\
\hline III:5 & M & 1923 & 172 & 67 & $130 / 70$ & 1.79 & Type III AD treated in 1976 & - & - \\
\hline III:7 & M & 1925 & $<175$ & - & - & - & Died in 1978 ( 53 years old) from stroke & - & - \\
\hline III:9 & $\mathrm{F}$ & 1927 & $<160$ & - & - & - & $\begin{array}{l}\text { Died in } 1992 \text { following the surgery of a right } \\
\text { intracranial carotid aneurysm }\end{array}$ & - & - \\
\hline III:11 & $\mathrm{F}$ & 1929 & $<160$ & - & - & - & Died from stroke at 66 years old & - & - \\
\hline IV:1 & M & 1939 & $<175$ & - & - & - & $\begin{array}{l}\text { SD during a great effort at } 49 \text { years old, violent } \\
\text { thoracic pain (no autopsy) }\end{array}$ & - & - \\
\hline IV:3 & $\mathrm{F}$ & 1946 & 164 & 73 & $110 / 60$ & 1.79 & PDA treated at 10 years old & $2 / 30$ & $35 / 28 / 23 / 20$ \\
\hline IV:5 & $\mathrm{F}$ & 1955 & 156 & 51 & $115 / 70$ & 1.48 & Borderline measurements & $2.1 / 28$ & 28/22/20/19 \\
\hline IV:7 & $\mathrm{F}$ & 1948 & 155 & - & $140 / 70$ & - & Chronicle type III AD & - & - \\
\hline IV:9 & M & 1948 & 174 & 64 & $130 / 70$ & 1.76 & $\begin{array}{l}\text { PDA and ascending TAA detected by this study } \\
\text { without Al }\end{array}$ & $2.2 / 34$ & $40 / 34 / 25 / 32$ \\
\hline IV:10 & $\mathrm{F}$ & 1947 & $<160$ & - & - & - & $\begin{array}{l}\text { SD at } 42 \text { years old at the time of an effort } \\
\text { (no autopsy) }\end{array}$ & - & - \\
\hline IV:11 & M & 1949 & 172 & 68 & $95 / 60$ & 1.8 & TAA detected by this study without Al & $2.4 / 35$ & $50 / 36 / 28 / 26$ \\
\hline IV:13 & M & 1951 & 166 & 70 & $120 / 80$ & 1.79 & $\begin{array}{l}\text { TAA without Al, PDA spontaneously closed } \\
\text { ( } 27 \text { years old) }\end{array}$ & $2.2 / 39$ & $43 / 40 / 29 / 24$ \\
\hline IV:19 & $\mathrm{F}$ & 1956 & 150 & 47 & $130 / 70$ & 1.39 & Discordant aortic measurements & $2.2 / 27$ & $27 / 21 / 14 / 20$ \\
\hline IV:20 & $\mathrm{F}$ & 1959 & $<165$ & - & - & - & PDA treated at 9 years old & & \\
\hline & & & & & & & $\begin{array}{l}\text { Died from an acute type III AD at } 8 \text { month of } \\
\text { gestation }\end{array}$ & - & - \\
\hline IV:21 & M & 1964 & 171 & 74 & $120 / 70$ & 1.86 & Borderline/discordant measurements & $2.1 / 38$ & $38 / 38 / 24 / 20$ \\
\hline IV:22 & M & 1969 & 173 & 65 & $120 / 70$ & 1.78 & $\begin{array}{l}\text { Ascending dissecting aneurysm type II } \\
\text { (Figure } 2 \mathrm{a} \text { and } \mathrm{b} \text { ) }\end{array}$ & $3.5 / 60$ & $65 / 60 / 32 / 30$ \\
\hline IV:26 & $\mathrm{F}$ & 1956 & - & - & - & - & $\begin{array}{l}\text { Died in } 1977 \text { ( } 21 \text { years old) from a left } \\
\text { intracranial carotid dissection }\end{array}$ & - & - \\
\hline IV:27 & $\mathrm{F}$ & 1964 & 160 & 57 & $130 / 70$ & 1.58 & Borderline/discordant measurements & $2.1 / 34$ & $35 / 29 / 20 / 18$ \\
\hline IV:28 & $\mathrm{F}$ & 1966 & 152 & 47 & $120 / 70$ & 1.43 & Borderline/discordant measurements & $2.3 / 33$ & $32 / 28 / 18 / 17$ \\
\hline $\mathrm{V}: 4$ & $\mathrm{M}$ & 1971 & 155 & 100 & $120 / 60$ & 1.92 & Borderline/discordant measurements & $1.8 / 36$ & $38 / 35 / 24 / 24$ \\
\hline V:6 & $\mathrm{M}$ & 1979 & 174 & 68 & $130 / 75$ & 1.81 & Borderline/discordant measurements & $2.1 / 32$ & $37 / 30 / 18 / 18$ \\
\hline $\mathrm{V}: 9$ & $\mathrm{~F}$ & 1975 & 160 & 47 & $120 / 60$ & 1.46 & PDA treated at 2 years old & $1.7 / 26$ & $34 / 28 / 20 / 22$ \\
\hline V:13 & $\mathrm{M}$ & 1975 & 179 & 73 & $120 / 60$ & 1.91 & TAA without Al & $2.2 / 39$ & $41 / 39 / 24 / 28$ \\
\hline V:15 & $\mathrm{M}$ & 1974 & 176 & 68 & $110 / 60$ & 1.83 & Borderline/discordant measurements & $2.1 / 35$ & $38 / 36 / 28 / 25$ \\
\hline $\mathrm{V}: 21$ & $\mathrm{M}$ & 1992 & - & - & - & - & PDA treated at 1 year old & - & - \\
\hline $\mathrm{V}: 22$ & $\mathrm{M}$ & 1994 & 110 & 17 & $95 / 53$ & 0.75 & $\begin{array}{l}\text { PDA detect by this study and treated at } 6 \text { years } \\
\text { old }\end{array}$ & 2.66 & - \\
\hline$V: 23$ & $\mathrm{~F}$ & 1997 & - & - & - & - & $\begin{array}{l}\text { PDA detect by this study and treated at } 3 \text { years } \\
\text { old (Figure } 2 c \text { ) }\end{array}$ & - & - \\
\hline
\end{tabular}

TAA, thoracic aortic aneurysm; AD, aortic dissection; PDA, patent ductus arteriosus; SD, sudden death; - , not known or not performed; TTE, transthoracic echocardiography; Al, aortic insufficiency. 

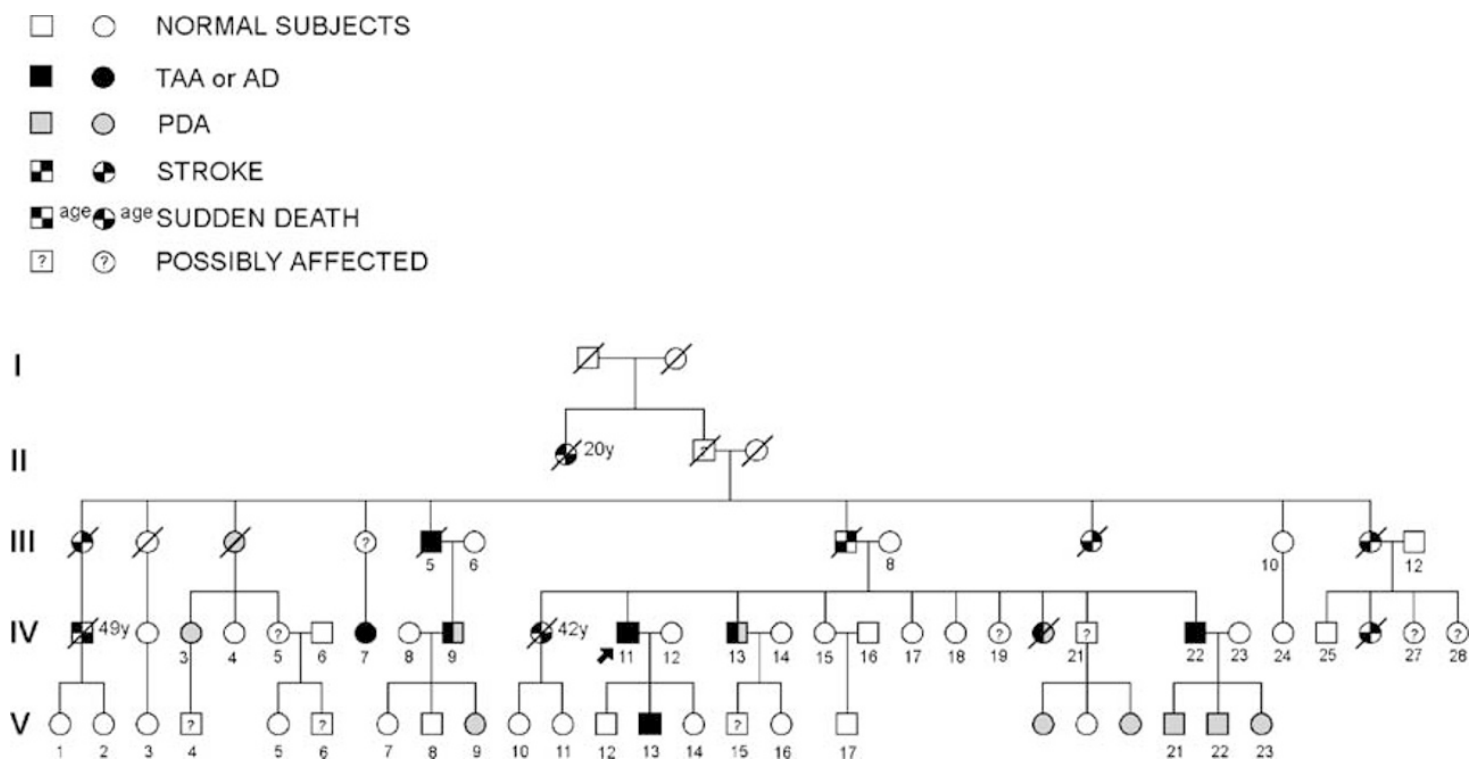

Figure 1 The 'Bourgogne' family tree affected by TAA/AD and PDA. To simplify the figure, only subjects enrolled in this study have been numbered.

including PDA cases in linkage analysis, we defined a supplemental liability class with a phenocopy rate fixed at $1 / 2000^{22}$ and a penetrance rate of $90 \%$. The linkage analyses were performed using the M-LINK program implemented in the Linkage Package. ${ }^{23}$

\section{Results}

\section{Characterization of the pedigree (Figure 1)}

There were eight cases of TAA $(n=4)$ and $\mathrm{AD}(n=4)$ in three generations, compatible with an autosomal dominant pattern of inheritance. The main characteristics and medical history of the affected subjects are indicated in Table 1 and Figure 2. During the screening, four asymptomatic TAA were diagnosed (IV:9, IV:11, IV:13 and V:13). All corresponded to a dilatation of the aortic root with measurements in excess of $2.1 \mathrm{~cm} / \mathrm{m}^{2}$ (aortic sinuses) at echocardiography and $40 \mathrm{~mm}$ (aortic sinuses) at MRI. In all these individuals, a normal tricuspid aortic valve was observed. In addition to the TAA reported above, a large number of vascular events occurred in this family (Figure 1): five cases of stroke, two of which occurred due to a documented intracranial carotid aneurysm (III:9 and IV:26), and three cases of unexplained sudden death (II:1, IV:1, IV:10), two of which occurred during an unusually violent effort.

Among the subjects investigated, we found 11 cases of PDA (Table 1). None had a history of neonatal problems. Subject IV:20 who died from AD was surgically treated for PDA. All the PDA cases seem to cosegregate in an autosomal dominant pattern of inheritance with cases of TAA/AD (Figure 1).
It is important to note that for all 40 subjects examined, except aortic abnormalities, there were neither signs of MFS, EDS vascular type and Char syndrome, ${ }^{24}$ nor valve abnormalities. There was no family history of arterial hypertension or dyslipidemia. Histological examinations of the aorta were performed postoperatively for subjects III:5, IV:11 and IV:22. Lesions consisted of medial degeneration with disruption of the medial elastic fibers, smooth muscle disorganization with deposits of mucopolysaccharide-like material. These abnormalities favor the hypothesis of an intrinsic vascular abnormality.

\section{Segregation analysis}

Segregation analysis was performed using the computer program REGRESS ${ }^{18}$ that allows to estimate the genetic parameters of inheritance ( $q$ : the disease allele frequency and $\alpha_{\mathrm{AA}}, \alpha_{\mathrm{Aa}}, \alpha_{\mathrm{aa}}$ : the genotype-specific baseline parameters). The sporadic model was rejected against the codominant one $\left(\chi^{2}(3 \mathrm{df})=9.47 ; P=0,02\right)$. A model of the dominant pattern of inheritance was significantly better than a codominant one $\left(\chi^{2}(1 \mathrm{df}=3,7 ; P=0.05)\right)$. The recessive model was not rejected against the codominant one $\left(\chi^{2}(1 \mathrm{df}=0.05 ; P=0.99)\right)$.

The best genetic model was a dominant biallelic locus with an allele disease frequency of 0.03 . Thus, the possibility of two distinct genetic defects remains possible but unlikely.

\section{Genetic linkage analysis}

Contributions of all the candidate loci were tested using at least two informative microsatellite markers at each locus (Table 2). Using first the affected-only TAA/AD phenotype 

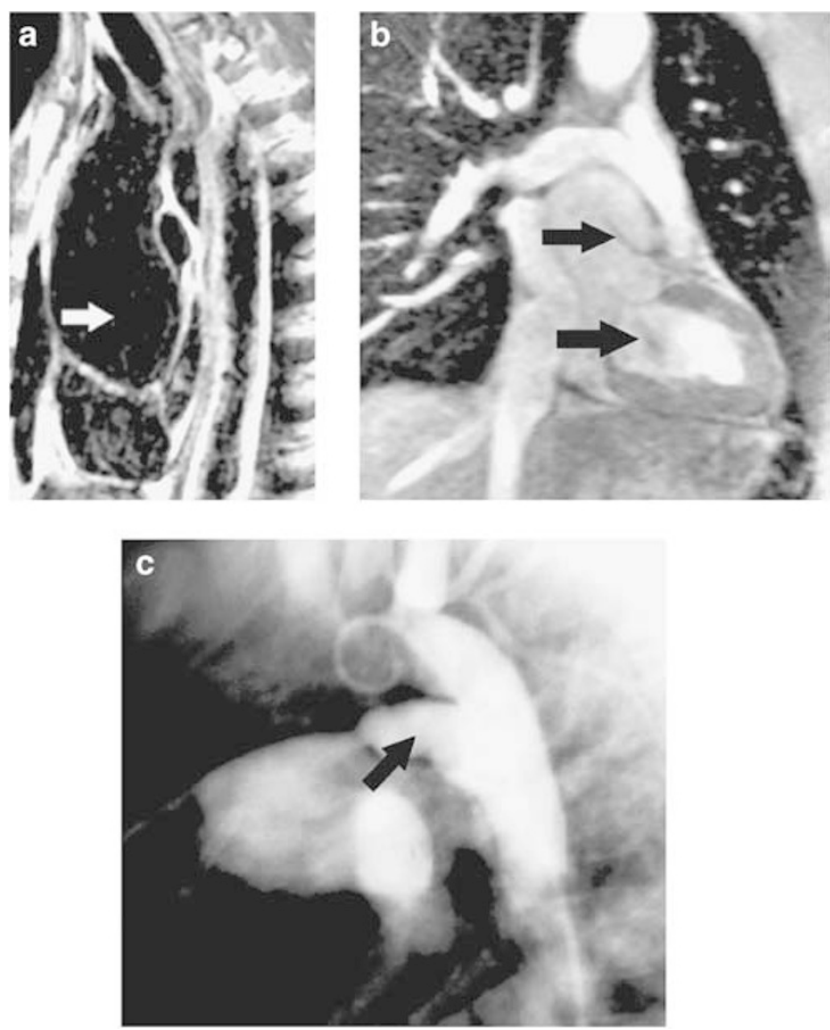

Figure $2 \mathrm{TAA} / \mathrm{AD}$ in one affected subject and PDA in his daughter. Preoperative MRI of subject IV:22 showing an aortic dissecting aneurysm type II. (a) Gated spin-echo T1 weighted; (b) cineMRI, the arrows show the aortic dissection and aortic valve incompetence. Operative picture of the trans-catheter PDA closure (Amplatz's duct) of the daughter, subject V:23 (c).

(PDA as unknown), two-point linkage analysis excluded linkage $(Z<-2)$ for all loci (Table 3). Changing values of penetrance or disease frequency had no effects on the exclusion (data not shown). When PDA-affected status was included, the exclusion values were even stronger. Multipoint linkage analysis confirmed the exclusion of linkage for all the loci tested (data not shown). Consequently, another gene is implicated in this family.

\section{Discussion}

The careful analysis of 40 members of one large French family in which cardiovascular events, TAA, AD and PDA occurred at a high frequency provides strong arguments for a particular pathological entity that associates TAA/AD and PDA. Such an entity was suggested by Glancy et $\mathrm{al}^{13}$ who described a single family where TAA/AD and PDA occur in three generations with an apparent autosomal dominant inheritance. In both Glancy's report and ours, no other features of typical connective disorders were observed, strongly suggesting a similar genetic defect. Teien $e t a^{25}$ also described the presence of TAA/AD and PDA cases within a small family. The analysis of our pedigree further demonstrates the likelihood of a unique gene causing PDA and TAA/AD, and allows the exclusion of the genes causing MFS and EDS vascular-type syndromes and of three loci previously linked to nonsyndromic TAA/AD. ${ }^{9-11}$ Histological examinations of aortic samples from three affected members of our family revealed medial degeneration that is known to occur but not specifically, in connective tissue diseases such as MFS and vascular EDS, in association with TAA/AD. Linkage to these loci, as well as linkage to the loci on chromosomes $3,{ }^{11} 5^{9}$ and 11 was ruled out. ${ }^{10}$ Moreover, DNA sequencing of COL3A1 cDNA in three affected subjects detected no mutation within the entire coding sequence (data not shown). The exclusion of linkage was even stronger when subjects with PDA were considered to be affected rather than as unknown.

The identification of the genes involved in the pathogenesis of TAA/AD disease can be seriously hampered by: (1) the late onset of the disease; (2) the high mortality with a high incidence of sudden death; (3) the incomplete and age-dependent penetrance; (4) the difficulties inherent to the echo-Doppler and MRI screening; (5) the likely genetic heterogeneity; and (6) the occurrence of various cardiovascular events within the same family. Conversely, genetic analysis of particular large families such as those studied herein can more easily lead to substantial results. The large number of subjects with PDA $(n=11)$ compared to the average incidence of $1 / 2000$ in general population, ${ }^{22}$ its presence in three subjects with $\mathrm{TAA}$ or $\mathrm{AD}$, and its cosegregation with TAA/AD (Figures 1 and 2) and the results of the segregation analysis strongly suggest the presence of a unique autosomal dominant genetic defect. None of the cases observed in this family occurred in the presence of particular neonatal circumstances such as those usually observed in sporadic PDA. ${ }^{26,27}$ Besides, none of the examined subjects exhibited dysmorphism or hand anomalies that may indicate Char syndrome ${ }^{24}$ or other polymalformative conditions. Gelb et $a l^{28}$ described in a unique family a new heart-hand syndrome resembling Char syndrome with mild dysmorphism, hand anomalies, PDA, bicuspid aortic valves and aortic root abnormalities. These characteristics were not observed in our family, especially bicuspid aortic valves, known to be an important cause of TAA/AD type I/II. ${ }^{29,30}$ Thus, familial TAA/AD with PDA is likely to be a particular pathophysiological entity. From the analysis of our family, it is difficult to distinguish if $\mathrm{TAA}, \mathrm{AD}$ and $\mathrm{PDA}$ or even stroke with carotid artery aneurysms/dissections aneurysm correspond to some phenotypic heterogeneity or to incomplete penetrance of the same genetic defect. One of the difficulties is due to the possibility of asymptomatic or paucisymptomatic PDA and to a possible underestimation of its presence unless a 
Table 2 Microsatellite markers at the candidate loci and genes

\begin{tabular}{|c|c|c|c|c|}
\hline Locus/marker & Nature & Heteroz & Position & Position from $p$-ter (cM) \\
\hline \multicolumn{5}{|l|}{$\operatorname{COL} 3 A 1$} \\
\hline HUMCOL3A1B 34 & VNTR & 0.73 & COL3A1 (Intron 25) & 190.0 \\
\hline $\mathrm{D} 2 \mathrm{~S} 118^{35}$ & $(A C) n$ & 0.79 & $<0.01 \mathrm{cM} / \mathrm{COL} 3 \mathrm{~A} 1$ & 190.0 \\
\hline \multicolumn{5}{|l|}{ FBN1 } \\
\hline HUMFBN1-I (mts-1) 36 & $(A C) n$ & 0.58 & Intragenic at $1.1 \mathrm{cM}$ from FBN1 locus & 38.1 \\
\hline D15S117 35 & $(A C) n$ & 0.78 & & 37.0 \\
\hline \multicolumn{5}{|l|}{ MFS2-TAAD2 } \\
\hline D3S2338 11,12 & $(A C) n$ & 0.93 & Both distant from $10.5 \mathrm{cM}$, surrounding the MFS2 locus & 42.1 \\
\hline D3S1266 11,12 & $(A C) n$ & 0.79 & & 52.6 \\
\hline \multicolumn{5}{|l|}{ TFAP $2 B$} \\
\hline D6S269 35 & $(A C) n$ & 0.71 & Both distant from $1.15 \mathrm{cM}$, surrounding $T F A P 2 B$ & 73.1 \\
\hline D6S465 35 & $(A C) n$ & 0.61 & & 74.2 \\
\hline \multicolumn{5}{|l|}{$5 q 13-q 14-T A A D 1$} \\
\hline D5S20299-35 & $(A C) n$ & 0.89 & All linked to the $5 q 13-q 14$ locus & 92.4 \\
\hline D5S641 $9-35$ & $(A C) n$ & 0.85 & & 92.4 \\
\hline MAP1B 37 & $(A C) n$ & 0.71 & & 92.4 \\
\hline \multicolumn{5}{|l|}{$11 q 23.2-q 24-F A A 1$} \\
\hline D11S4195 $10-35$ & $(A C) n$ & 0.75 & Spaced of $3 \mathrm{cM}$ in the $11 \mathrm{q} 23.2-\mathrm{q} 24$ locus & 113.4 \\
\hline D11S924 ${ }^{10,35}$ & $(A C) n$ & 0.79 & & 115.5 \\
\hline D11S4132 10,35 & $(A C) n$ & 0.82 & & 116.1 \\
\hline \multicolumn{5}{|l|}{$12 q 24$ (with PTPN11): } \\
\hline D12S78 33,35 & $(A C) n$ & 0.86 & PTPN11 & 118.5 \\
\hline $\mathrm{D} 12 \mathrm{~S} 86^{33,35}$ & $(A C) n$ & 0.93 & Spaced of $13.5 \mathrm{cM}$ & 140.3 \\
\hline $\mathrm{D} 12 \mathrm{~S} 324^{33,35}$ & $(A C) n$ & 0.64 & Surrounding the $12 q 24$ locus & 153.8 \\
\hline
\end{tabular}

Table 3 Results of Two-point linkage analysis at candidate loci and genes

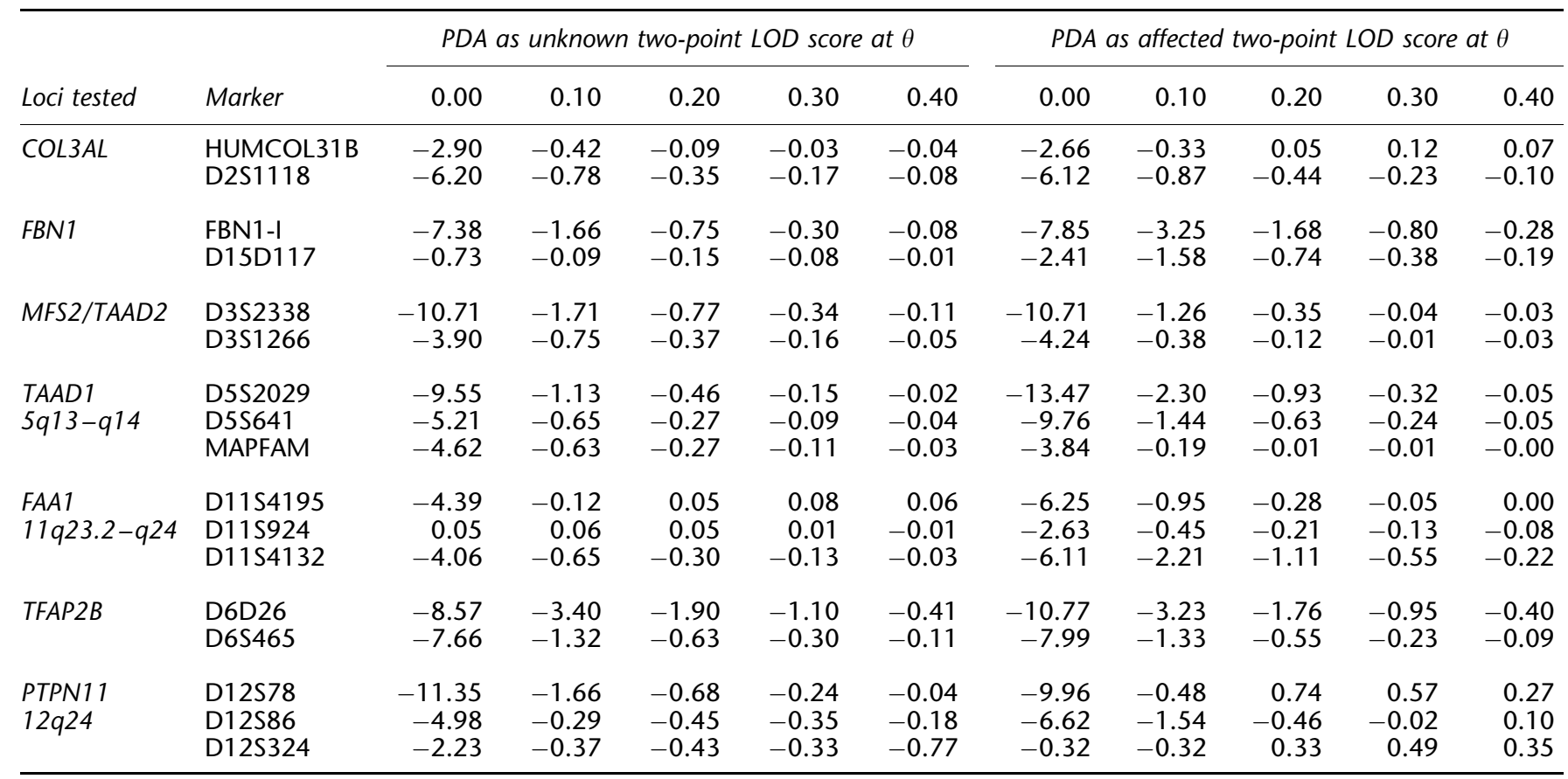


systematic investigation is conducted. Indeed, six out of 11 of our PDA cases were discovered by echo-Doppler thanks to our screening. The systematic follow-up of the family members might allow us to evaluate the risk of TAA/AD for offspring with apparently isolated PDA. Identification of the causal gene will help to study its role in the overall PDA and TAA/AD cases. Currently, the only identified causal gene is TFAP2B, a transcription factor that is expressed in neural crest cells and responsible for CHAR syndrome. ${ }^{24}$ The absence of facial abnormalities and other malformations in our family as well as in the ones described by Teien et $a l^{25}$ and Glancy et $a l^{13}$ strongly suggests that another causal gene and genetic linkage analysis ruled out the implication of that locus in our family (Table 3), but not the influence of possible coactivators. ${ }^{31}$ Recently, Mani et $a l^{32}$ reported a recessive locus at $12 \mathrm{q} 24$ that commonly contributes to PDA. Our genetic linkage analysis assuming a dominant model and a variable penetrance excluded this locus. Incidentally, this genetic analysis also excluded the responsibility of the PTPN11 gene, whose defects have been implied in the Noonan syndrome in which TAA and PDA might exist. ${ }^{33}$

PDA might also be one of the primary signs of neural crest malfunction, even though in that case it is usually accompanied by aortic arch anomalies, as in the DiGeorge syndrome. We thus analyzed the karyotype of subject IV:13 affected by both PDA and AAT using standard fluorescent hybridization in situ. No 22q11.2 microdeletion was observed. An alternative mechanism relating PDA and TAA/AD might be a gene expressed in the vascular wall that would affect the physiological changes of this aortic arch artery with advancing gestation, prevent its regression and apoptosis and at the same time favor a long-term fragility of the aortic vascular wall.

In conclusion, familial TAA/AD and PDA association may be a new recognizable entity where subjects with PDA could have a particular risk of TAA/AD. Further genetic analysis should help to elucidate the molecular mechanisms responsible for the TAA/AD/PDA syndrome.

\section{Acknowledgements}

We thank first the members of the 'Bourgogne family' for participating in this study and INSERM, the Fondation pour la Recherche Médicale, the Association de Cardiologie de Bourgogne and the Association Claude Bernard for their financial support as well as Nathalie Khau Van Kien, Dr Caroline Bulté, Dr Annie Petit, Dr Elisabeth Devilliers, Dr Marie-Thérèse Zabot, Pr Michel David and Pr Pierre Corvol for their contribution to the study.

\section{References}

1 Svensjo S, Bengtson H, Bergqvist D: Thoracic and thoracoabdominal aortic aneurysm and dissection: an investigation based on autopsy. Br J Surg 1996; 83: 68-71.
2 Meszaros I, Morocz J, Szlavi J, Tornoci L, Nagy L, Szep L: Epidemiology and clinicopathology of aortic dissection. Chest 2000; 117: 1271-1278.

3 Coady MA, Davies RR, Roberts $M$ et al: Familial patterns of thoracic aortic aneurysms. Arch Surg 1999; 134: 361-367.

4 Beighton P, De Paepe A, Steinmann B, Tsipouras P, Wenstrup RJ: Ehlers-Danlos syndromes: revised nosology, Villefranche, 1997. Am J Med Genet 1998; 77: 31-37.

5 Kontusaari S, Kuivaniami H, Tromp G, Grimwood R, Prockop DJ: A single base mutation in type III procollagen that converts the codon for glycine 619 to arginine in a family with aortic aneurysm. Ann NY Acad Sci 1990; 580: 556-557.

6 Kontusaari S, Tromp G, Kuivaniami H, Ladda RL, Prockop DJ: Inheritance of an RNA splicing mutation $(\mathrm{G}(+1)$ IVS20) in the type III procollagen gene (COL3A1) in a family having aortic aneurysms and easy bruisability: phenotypic overlap between familial arterial aneurysm and Ehlers-Danlos syndrome type IV. Am J Hum Genet 1990; 47: 112-120.

7 Francke U, Berg MA, Tynan K et al: A Gly1127Ser mutation in an EGF-like domain of the fibrillin-gene is a risk factor for ascending aortic aneurysm and dissection. Am J Hum Genet 1995; 56: $1287-1296$.

8 Milewicz DM, Michael K, Fisher N, Coselli JS, Markello T, Biddinger A: Fibrillin-1 (FBN1) mutations in patients with thoracic aortic aneurysms. Circulation 1996; 94: $2708-2711$.

9 Guo D, Hasham S, Kuang SQ et al: Familial thoracic aortic aneurysms and dissections: genetic heterogeneity with a major locus mapping to 5q13-14. Circulation 2001; 103: $2461-2468$.

10 Vaughan CJ, Casey M, He J et al: Identification of a chromosome 11q23.2-q24 locus for familial aortic aneurysm disease, a genetically heterogeneous disorder. Circulation 2001; 103: $2469-2475$.

11 Hasham SN, Willing MC, Guo DC et al: Mapping a locus for Familial Thoracic Aortic Aneurysms and Dissection (TAAD2) to 3p24-25. Circulation 2003; 107: 3184-3190.

12 Collod G, Babron MC, Jondeau G et al: A second locus for Marfan syndrome maps to chromosome 3p24.2-p25. Nat Genet 1994; 8: 264-268.

13 Glancy DL, Wegmann M, Dhurandhar RW: Aortic dissection and patent ductus arteriosus in three generations. Am J Cardiol 2001; 87: 813-815.

14 Roman MJ, Devereux RB, Kramer-Fox R, O'Loughlin J: Twodimensional echocardiographic aortic root dimension in normal children and adults. Am J Cardiol 1989; 64: 507-512.

15 Higgins CB: The vascular system. In Higgins CB, Hricak H, Helms CA (eds): Magnetic resonance imaging of the body. New York: Lippincott-Raven, 1987, pp 309-346.

16 Cohen GI, White M, Shochowski RA et al: Reference values for normal adult transesophageal echocardiographic measurements. J Am Soc Echocardiogr 1995; 8: 221-230.

17 Bonney GE: Regressive logistic models for familial disease and other binary traits. Biometrics 1986; 42: 611-625.

18 Demenais F, Lathrop M: REGRESS: a computer program including the regressive approach into the LINKAGE package. Genet Epidemiol 1994; 11: 291.

19 Elston RC, Stewart J: A general model for the genetic analysis of pedigree data. Hum Hered 1971; 21: 523-542.

20 Sambrook J, Fritsch EF, Maniatis T: Molecular cloning: a laboratory manual. New York: Cold Spring Harbor Laboratory; 1989.

21 Milewicz DM, Chen H, Park ES et al: Reduced penetrance and variable expressivity of familial thoracic aortic aneurysms/ dissections. Am J Cardiol 1998; 82: 474-479.

22 Vaughan CJ, Basson CT: Molecular determinants of atrial and ventricular septal defects and patent ductus arteriosus. Am J Med Genet (Semin Med Genet) 2001; 97: 304-309.

23 Lathrop GM, Lalouel JM, Julier C, Ott J: Strategies for multilocus linkage analysis in humans. Proc Natl Acad Sci USA 1984; 81: $3443-3446$ 
24 Satoda M, Zhao F, Diaz GA et al: Mutations in TFAP2B cause Char syndrome, a familial form of patent ductus arteriosus. Nat Genet 2000; 25: 42-46.

25 Teien D, Finley JP, Murphy DA, Lacson A, Longhi J, Gillis DA: Idiopathic dilatation of the aorta with dissection in a family without Marfan syndrome. Acta Paediatr Scand 1991; 80: 1246-1249.

26 Clyman RI: Developmental physiology of the ductus arteriosus. in Brand $\mathrm{M}$ (ed): Fetal and neonatal cardiology. New York: Lippincott-Raven, 1997, pp 64-75.

27 Smith GCS: The pharmacology of the ductus arteriosus. Pharmacol Rev 1998; 50: 35 -58.

28 Gelb BD, Zhang J, Sommer RJ, Wasserman JM, Reitman MJ, Willner JP: Familial patent ductus arteriosus and bicuspid aortic valve with hand anomalies: a novel heart-hand syndrome. Am J Med Genet 1999; 87: 175-179.

29 Larson EW, Edwards WD: Risk factors for aortic dissection: a necropsy study of 161 cases. Am J Cardiol 1984; 53: 849-855.

30 Epperlein S, Mohr-Kahaly S, Erbel R, Kearney P, Meyer J: Aorta and aortic valve morphologies predisposing to aortic dissection. An in vivo assessment with transoesophageal echocardiography. Eur Heart J 1994; 15: 1520-1527.
31 Zhao F, Weismann CG, Satoda $M$ et al: Novel TFAP2B mutations that cause Char syndrome provide a genotype-phenotype correlation. Am J Hum Genet 2001; 69: 695-703.

32 Mani A, Meraji SM, Houshyar $\mathrm{R}$ et al: Finding genetic contributions to sporadic disease: a recessive locus at $12 \mathrm{q} 24$ commonly contributes to patent ductus arteriosus. Proc Natl Acad Sci USA 2002; 99: 15054-15059.

33 Digilio MC, Marino B, Picchio F et al: Noonan syndrome and aortic coarctation. Am J Med Genet 1998; 80: 160-162.

34 Mays PK, Tromp G, Kuivaniemi H, Ryynanen M, Prockop DJ: A 15 base-pair AT-rich variable number tandem repeat in the type III procollagen gene (COL3A1) as an informative marker for 2q31-2q32.3. Matrix 1992; 12: 44-49.

35 Weissenbach J, Gyapay G, Dib C et al: A second-generation linkage map of the Human genome. Nature 1992; 359: 794-801.

36 Pereira L, Levran O, Ramirez F et al: A molecular approach to the stratification of cardiovascular risk in families with Marfan's syndrome. N Engl J Med 1994; 331: 148-153.

37 Brzustowicz LM, Kleyn PW, Boyce FM et al: Fine-mapping of the spinal muscular atrophy locus to a region flanked by MAP1B and D5S6. Genomics 1992; 13: $991-998$. 